Check for updates

Cite this: J. Mater. Chem. A, 2017, 5 , 20289

Received 14th August 2017

Accepted 6th September 2017

DOI: $10.1039 / \mathrm{c} 7 \mathrm{ta} 07158 \mathrm{~b}$

rsc.li/materials-a

\section{Synthesis and characterization of novel stellate sea-urchin-like silver particles with extremely low density and superhydrophobicity $\dagger$}

\author{
S. I. Sadovnikov (D) * and A. I. Gusev (D) \\ Stellate sea-urchin-like silver particles with 24 to 56 rays of 30-50 $\mu \mathrm{m}$ in length have been synthesized by \\ chemical reduction of silver nitrate aqueous solution by thiocarbamide alkaline solution. The synthesis was \\ carried out under solar irradiation at room temperature. The stellate Ag particles are hydrophobic; their \\ relative density is smaller than that of water. By varying the $\mathrm{pH}$ and the ratio between the concentrations \\ of reagents, it is possible to produce fine-dispersed silver powders and films from stellate particles with \\ different ray lengths.
}

\section{Introduction}

Fine-dispersed silver powders are used in the production of catalysts, ${ }^{1,2}$ chemical current sources ${ }^{3}$ and electrical contacts and electrodes, ${ }^{4}$ for water treatment, ${ }^{5,6}$ as well as in biology and medicine as a material exerting a bactericidal effect., ${ }^{7,8}$ Owing to the combination of roughness and hydrophobicity, coating of conduit walls with fine-dispersed silver powder may promote fabrication of superhydrophobic surfaces ${ }^{9-11}$ and wall slippage of chemically aggressive liquids in conduits, thus increasing their service life. Protective silver coatings are most often used as thin $\mathrm{Ag}$ films ${ }^{11,12}$ or polymer films with $\mathrm{Ag}$ nanoparticles. ${ }^{13}$ In addition, thin silver films find applications in microelectronics. ${ }^{14}$ Among vapour deposition methods for thin Ag films, chemical vapour deposition has superior step coverage and can be easily scaled up to deposit high purity films on larger areas. ${ }^{12}$

Fine-dispersed silver powders are produced by different methods, including polyol synthesis, ${ }^{4,15,16}$ chemical and photochemical reduction ${ }^{1,17}$ hydro- and solvothermal synthesis, ${ }^{18,19}$ and green biosynthesis. ${ }^{20}$ Note that the formation of silver particles as an impurity is often observed during chemical synthesis of silver sulfide. ${ }^{21,22}$ Electrolysis is widely used in the production of silver powders. ${ }^{23,24}$ Silver nanodendrites are synthesized by electrodeposition ${ }^{25}$ and reduction from $\mathrm{AgNO}_{3} .{ }^{26}$ In physical processes, $\mathrm{Ag}$ particles are generally synthesized by evaporation-condensation method or by laser ablation of metallic bulk materials in solution. ${ }^{27-30}$

Silver nanoparticles usually have a spherical shape. In the last decade a new trend appeared connected with the

Institute of Solid State Chemistry, Ural Branch of the Russian Academy of Sciences, Ekaterinburg 620990, Russia. E-mail: sadovnikov@ihim.uran.ru

$\dagger$ Electronic supplementary information (ESI) available: Estimation of the relative density $\rho_{\text {stell }}$ and specific surface area $S_{\text {sp }}$ of stellate Ag particles. See DOI: 10.1039/c7ta07158b production of non-spherical Ag particles of different morphology (flat triangles, ${ }^{31}$ plates,${ }^{32}$ cubes,${ }^{15}$ prisms,${ }^{31}$ rods,${ }^{33}$ wires ${ }^{4,33}$ nano- and microdendrites, ${ }^{24-26}$ etc.).

The preparation of sea-urchin-like particles of copper, ${ }^{34}$ nickel, ${ }^{35,36}$ zinc oxide doped with iron,,$^{37}$ and silver ${ }^{38}$ by different methods is described in the literature. To date, there are no publications devoted to the synthesis and properties of stellate $\mathrm{Ag}$ particles.

In this work, fine-dispersed powders of silver metal with a specific morphology of stellate sea-urchin-like multi-ray particles have been produced by a simple green method of silver nitrate reduction.

\section{Experimental details}

For the synthesis of fine-dispersed $\mathrm{Ag}$ powders we used aqueous solutions of silver nitrate $\mathrm{AgNO}_{3}$ and thiocarbamide $\left(\mathrm{NH}_{2}\right)_{2} \mathrm{CS}$ with concentrations of 0.05 and $0.05 \mathrm{~mol} \mathrm{l}^{-1}$ and a $25 \%$ aqueous solution of ammonia (ammonium hydroxide $\mathrm{NH}_{4} \mathrm{OH}$ with a concentration of $\left.\sim 10.0 \mathrm{~mol} \mathrm{l}^{-1}\right)$.

The $\mathrm{pH}$ value of the solutions was controlled by a $\mathrm{pH} /$ conductivity/TDS Tester HI 98130 ionometer (Hanna Instruments).

The synthesized deposits (powders) and films were examined using a Shimadzu XRD-7000 diffractometer and a STADI-P (STOE) diffractometer in $\mathrm{CuK \alpha}_{1,2}$-radiation in the angle interval $2 \theta=15-110^{\circ}$ with a step of $\Delta(2 \theta)=0.02^{\circ}$ and a scanning time of $10 \mathrm{~s}$ per point. The crystal lattice parameters were determined and the final structure refinement was carried out with the use of the X'Pert software suite. ${ }^{39}$ The qualitative and quantitative phase compositions were estimated by means of the Match! Version 1.10 program package. ${ }^{40}$

The morphology of the synthesized fine-dispersed silver particles was studied by scanning electron microscopy (SEM) using a Jeol JSM LA 6390 microscope with a JED 2300 Energy 
Dispersive X-ray Analyzer. The elemental composition of $\mathrm{Ag}$ particles was carried out on the same microscope with the use of EDX analysis.

The optical reflectance spectra of the synthesized powders were measured on a Shimadzu UV-2401PC spectrophotometer and the optical absorption spectra of the synthesized films were obtained on an Edinburgh LP980 Fluorescence Spectrometer spectrofluorometer at $298 \mathrm{~K}$.

The density $\rho_{\text {stell }}$ of the synthesized fine-dispersed silver powders was determined on a Micromeritics AccuPyc II 1340 helium pycnometer.

The contact angle $\theta$ was measured with a Dataphysics OCA20 contact angle system at $298 \mathrm{~K}$. The average contact angle value was obtained by this measurement at three different positions of a water droplet on an $\mathrm{Ag}$ film surface formed on the glass substrate.

\section{Results and discussion}

The fine-dispersed Ag powders were synthesized by chemical reduction of $\mathrm{AgNO}_{3}$ in alkaline medium.

Mixed solutions with $\mathrm{pH}$ values ranging from 9 to 10 were prepared from the initial aqueous solutions of $\left(\mathrm{NH}_{2}\right)_{2} \mathrm{CS}$ and $\mathrm{NH}_{4} \mathrm{OH}$. Mixed solutions with $\mathrm{pH}=9$ were prepared by adding $0.005 \mathrm{ml}$ of $\mathrm{NH}_{4} \mathrm{OH}$ solution to $100 \mathrm{ml}$ of thiocarbamide solution. For the production of mixed solutions with $\mathrm{pH}>9,0.01$ to $0.5 \mathrm{ml}$ of ammonia solution was added to $100 \mathrm{ml}$ of thiocarbamide solution. In particular, the solution with $\mathrm{pH}=10$ was prepared by adding $0.5 \mathrm{ml}$ of $\mathrm{NH}_{4} \mathrm{OH}$ solution to $100 \mathrm{ml}$ of thiocarbamide solution. The concentrations of $\left(\mathrm{NH}_{2}\right)_{2} \mathrm{CS}$ and $\mathrm{NH}_{4} \mathrm{OH}$ in the mixed alkaline solution with $\mathrm{pH}=9$ were 50 and $0.5 \mathrm{mmol} \mathrm{l}^{-1}$, and in the mixed solution with $\mathrm{pH}=10$ they amounted to 50 and $50 \mathrm{mmol} \mathrm{l}^{-1}$ (Table 1 ). The concentration of $\mathrm{NH}_{4} \mathrm{OH}$ in the mixed solutions with intermediate $\mathrm{pH}$ values $(9<$ $\mathrm{pH}<10$ ) varied from 1 to $40 \mathrm{mmol} \mathrm{l}^{-1}$.

The fine-dispersed Ag powders were synthesized at room temperature under solar irradiation in the following way:

$10 \mathrm{ml}$ of mixed alkaline solution was gradually added to $100 \mathrm{ml}$ of the initial solution of $\mathrm{AgNO}_{3}$ with a concentration of $50 \mathrm{mmol}^{-1}$ at a rate of $0.005 \mathrm{ml} \mathrm{s}^{-1}$. The ratio of concentrations of silver nitrate, thiocarbamide and ammonium hydroxide $\left[\mathrm{AgNO}_{3}\right]:\left[\left(\mathrm{NH}_{2}\right)_{2} \mathrm{CS}\right]:\left[\mathrm{NH}_{4} \mathrm{OH}\right]$ in the reaction mixtures with different $\mathrm{pH}$ values ranged from $1: 0.1: 0.001$ to $1: 0.1: 0.1$. The duration of synthesis was $30-60 \mathrm{~min}$. The synthesized solution was kept in sunlight for one day. As a result, a layer of black deposit appeared on the bottom of the glass with the synthesized solution, a black film was formed on the walls, and a pale-yellow film emerged on the surface of the solution. The film collected from the surface of the solution was dried in air at $313 \mathrm{~K}$; as a result, a fine-dispersed powder was obtained. The quantitative X-ray diffraction (XRD) analysis revealed that this powder (or the pale-yellow surface film) is face-centered cubic (space group $F m \overline{3} m$ ) silver Ag with preferable orientation in the direction [111] (Fig. 1a). In addition, a weak peak is observed in the XRD pattern of the Ag film in the angle interval $2 \theta=34.1-34.5^{\circ}$; this peak corresponds to two neighboring diffraction reflections $(-122)$ and (022) of impurity monoclinic silver sulfide.

The quantitative analysis of the XRD pattern of the black deposit and the comparison with the XRD data ${ }^{41-43}$ showed that the observed set of diffraction reflections corresponds to monoclinic (space group $P 2_{1} / c$ ) silver sulfide $\mathrm{Ag}_{2} \mathrm{~S}$ (Fig. 1b). The appreciable broadening of the silver sulfide diffraction reflections (Fig. 1b) is indicative of the small size of the $\mathrm{Ag}_{2} \mathrm{~S}$ particles; the evaluation of the nanoparticle size from the broadening of non-overlapping reflections gives the value $D=50 \pm 8 \mathrm{~nm}$. The XRD pattern of $\mathrm{Ag}_{2} \mathrm{~S}$ also contains weak reflections of the second phase, which is cubic metallic Ag. According to the quantitative phase analysis data, the content of the metallic silver phase is equal to $\sim 7.5 \mathrm{wt} \%$.

For the second synthesis route, for the preparation of silver films we used a glass substrate. The synthesis was performed at room temperature under solar irradiation by successive ionic layer adsorption and reaction (SILAR). The substrate was sequentially immerged in a vessel with deionized distilled water, then into $\mathrm{AgNO}_{3}$ solution for $15 \mathrm{~s}$, then again into distilled water, and after that into a mixed alkaline solution (Fig. 2). This four-stage cycle was repeated from 15 to 30 times, and after each fifth cycle the vessels with water were changed for vessels with fresh deionized distilled water. Silver particles were

Table 1 Composition of the aqueous solutions and reaction mixtures, maximum distance $L_{\max }$ between the ends of the opposite rays of stellate Ag particles, relative density $\rho_{\text {stell }}$ and specific surface area $S_{\text {sp }}$ of Ag powders

\begin{tabular}{|c|c|c|c|c|c|c|c|c|c|c|c|}
\hline \multirow[b]{3}{*}{ No. } & \multicolumn{3}{|c|}{$\begin{array}{l}\text { Concentration of reagents in } \\
\text { aqueous solutions }\left(\mathrm{mmol}^{-1}\right)\end{array}$} & \multirow{3}{*}{$\begin{array}{l}\mathrm{pH} \text { of mixed } \\
\text { alkaline solution }\end{array}$} & \multicolumn{3}{|c|}{$\begin{array}{l}\text { Concentration of reagents in } \\
\text { reaction mixtures }\left(\mathrm{mmol} \mathrm{l}^{-1}\right)\end{array}$} & \multicolumn{4}{|c|}{ Stellate particles } \\
\hline & \multirow[b]{2}{*}{$\mathrm{AgNO}_{3}$} & \multicolumn{2}{|c|}{$\begin{array}{l}\text { Mixed alkaline } \\
\text { solution }\end{array}$} & & \multirow[b]{2}{*}{$\mathrm{AgNO}_{3}$} & \multirow[b]{2}{*}{$\left(\mathrm{NH}_{2}\right)_{2} \mathrm{CS}$} & \multirow[b]{2}{*}{$\mathrm{NH}_{4} \mathrm{OH}$} & \multirow{2}{*}{$\begin{array}{l}L_{\max } \pm 5 \\
(\mu \mathrm{m})\end{array}$} & \multirow{2}{*}{$\begin{array}{l}\rho_{\text {stell }} \pm 0.20 \\
\left(\mathrm{~g} \mathrm{~cm}^{-3}\right)\end{array}$} & \multicolumn{2}{|l|}{ Calculation } \\
\hline & & $\left(\mathrm{NH}_{2}\right)_{2} \mathrm{CS}$ & $\mathrm{NH}_{4} \mathrm{OH}$ & & & & & & & $\rho_{\text {stell }}{ }^{a}\left(\mathrm{~g} \mathrm{~cm}^{-3}\right)$ & $S_{\mathrm{sp}}^{b}\left(\mathrm{~m}^{2} \mathrm{~g}^{-1}\right)$ \\
\hline 1 & 50 & 50 & 0.5 & 9 & 50 & 5 & 0.05 & 60 & 0.40 & $0.21 \pm 0.01$ & $0.24-0.41$ \\
\hline 2 & 50 & 50 & 20 & 9.5 & 50 & 5 & 2.0 & 70 & 0.37 & $0.15 \pm 0.01$ & $0.25-0.42$ \\
\hline 3 & 50 & 50 & 50 & 10 & 50 & 5 & 5 & 80 & - & $0.12 \pm 0.01$ & $0.25-0.43$ \\
\hline
\end{tabular}



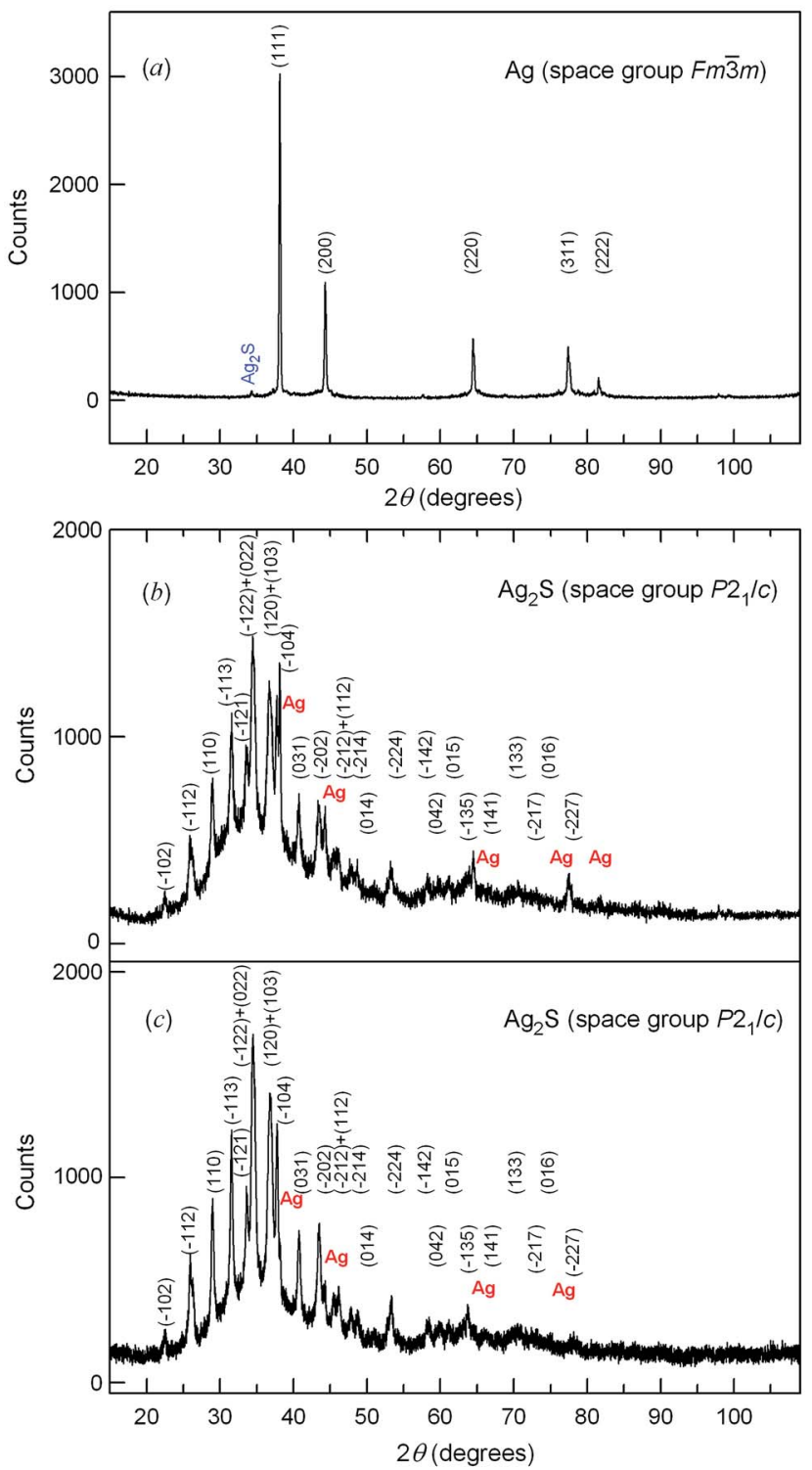

Fig. 1 (a) The XRD pattern of Ag film prepared on the surface of the reaction mixture of $\mathrm{AgNO}_{3},\left(\mathrm{NH}_{2}\right)_{2} \mathrm{CS}$ and $\mathrm{NH}_{4} \mathrm{OH}$ with concentrations 50,50 and $0.5 \mathrm{mmol} \mathrm{l}^{-1}$, respectively. ( $\mathrm{b}$ and c) XRD patterns of $\mathrm{Ag}_{2} \mathrm{~S}$ deposits prepared in the first and second synthesis routes on the bottom of vessels with the reaction mixtures. The XRD patterns of $\mathrm{Ag}_{2} \mathrm{~S}$ contain weak reflections of silver metal; the relative content of the metallic silver phase in the deposits (b) and (c) is $\sim 3.0$ and $\sim 7.5 \mathrm{wt} \%$. The XRD patterns are recorded in $\mathrm{CuK} \alpha_{1,2}$ radiation.

formed at the last stage of the cycle, when the substrate with $\mathrm{Ag}^{2+}$ ions adsorbed on the surface was immerged into the alkaline solution, where silver was reduced. The formation of a thin layer of bright yellow particles was visually observed on the "substrate-silver nitrate solution" interface. After 30 cycles, a black deposit in the form of a film appeared on the walls of the vessel with $\mathrm{AgNO}_{3}$ solution, and upon exposure of this solution to light for 1 day a yellow film was formed on its surface. The XRD patterns of the film that emerged on the surface of the solution and the film that formed on the substrate are similar to the XRD pattern in Fig. 1a and correspond to cubic Ag. The XRD

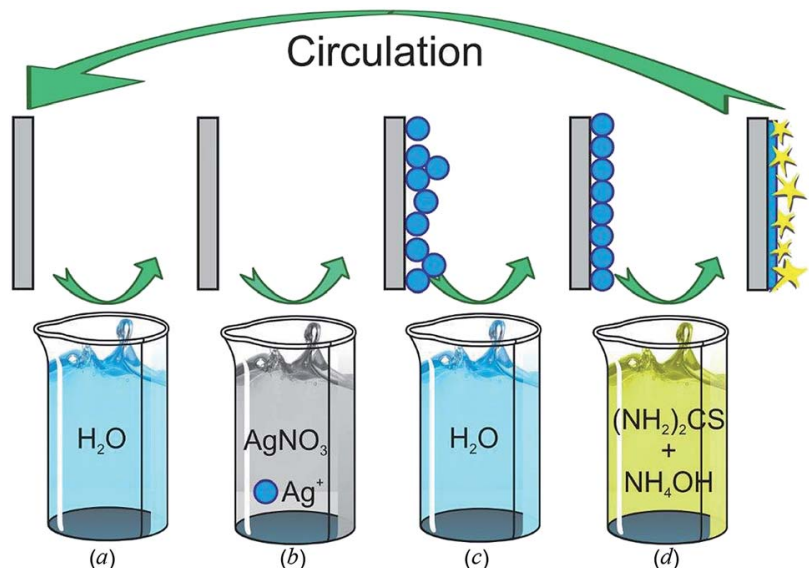

Fig. 2 The scheme of the second synthesis route by the SILAR method: ( $a$ and c) deionized distilled water, (b) solution of $\mathrm{AgNO}_{3}$, and (d) mixed alkaline solution.

pattern of the deposit (Fig. 1c) is identical to the XRD pattern (Fig. 1b) obtained from the same deposit in the first synthesis option and corresponds to nanocrystalline monoclinic sulfide $\mathrm{Ag}_{2} \mathrm{~S}$ with a small ( $\sim 3 \mathrm{wt} \%$ ) impurity of metallic $\mathrm{Ag}$.

Silver, as the main product of the synthesis, is formed as a result of several concurrent reactions.

The ammonia molecules bind $\mathrm{Ag}^{+}$ions into complex ions $\left[\mathrm{Ag}\left(\mathrm{NH}_{3}\right)_{2}\right]^{+}$. The thiocarbamide $\left(\mathrm{NH}_{2}\right)_{2} \mathrm{CS}$ in the alkaline aqueous solution is hydrolyzed with the formation of cyanamide $\mathrm{N}_{2} \mathrm{H}_{2} \mathrm{C}$ and $\mathrm{S}^{2-}$ ions. The solubility product $K_{\text {sp }}$ of silver sulfide is very small $\left(K_{\mathrm{sp}}=6.3 \times 10^{-50}\right.$ at $\left.298 \mathrm{~K}\right),{ }^{44}$ therefore the silver sulfide $\mathrm{Ag}_{2} \mathrm{~S}$ is always formed in the presence of $\mathrm{S}^{2-}$ ions in the aqueous solution of $\mathrm{AgNO}_{3}$. With this in mind, the deposition of $\mathrm{Ag}_{2} \mathrm{~S}$ from $\mathrm{AgNO}_{3},\left(\mathrm{NH}_{2}\right)_{2} \mathrm{CS}$ and $\mathrm{NH}_{4} \mathrm{OH}$ solutions take place through the following reactions:

$$
\begin{gathered}
\mathrm{AgNO}_{3}+2 \mathrm{NH}_{4} \mathrm{OH} \rightarrow\left[\mathrm{Ag}\left(\mathrm{NH}_{3}\right)_{2}\right] \mathrm{NO}_{3}+2 \mathrm{H}_{2} \mathrm{O} \\
\left(\mathrm{NH}_{2}\right)_{2} \mathrm{CS}+2 \mathrm{OH}^{-} \rightarrow \mathrm{N}_{2} \mathrm{H}_{2} \mathrm{C}+\mathrm{S}^{2-}+2 \mathrm{H}_{2} \mathrm{O} \\
2\left[\mathrm{Ag}\left(\mathrm{NH}_{3}\right)_{2}\right] \mathrm{NO}_{3}+\mathrm{S}^{2-} \rightarrow \mathrm{Ag}_{2} \mathrm{~S} \downarrow+2 \mathrm{NO}_{3}{ }^{-}+4 \mathrm{NH}_{3}
\end{gathered}
$$

Since our major task was to prepare a fine-dispersed silver powder, we performed the synthesis using a minimal amount of $\left(\mathrm{NH}_{2}\right)_{2} \mathrm{CS}$, which was insufficient for the deposition of all silver in the form of sulfide. In that case, the aqueous solution contained a large quantity of free complexes $\left[\mathrm{Ag}\left(\mathrm{NH}_{3}\right)_{2}\right] \mathrm{NO}_{3}$, which were reduced by cyanamide $\mathrm{N}_{2} \mathrm{H}_{2} \mathrm{C}$ to metallic $\mathrm{Ag}$ under solar irradiation at room temperature:

$$
\begin{aligned}
2\left[\mathrm{Ag}\left(\mathrm{NH}_{3}\right)_{2}\right] \mathrm{NO}_{3} & +\mathrm{N}_{2} \mathrm{H}_{2} \mathrm{C}+2 \mathrm{H}_{2} \mathrm{O} \stackrel{h v}{\longrightarrow} 2 \mathrm{Ag} \downarrow \\
& +2 \mathrm{NH}_{4} \mathrm{NO}_{3}+\mathrm{NH}_{4} \mathrm{CN}+2 \mathrm{NH}_{2} \mathrm{OH}
\end{aligned}
$$

The scanning electron microscopy of the silver metal film revealed that it is formed of stellate sea-urchin-like particles having from 24 to 56 pyramidal and wedge-shaped rays $30-50 \mu \mathrm{m}$ in length and a medium-sized core of 5-6 $\mu \mathrm{m}$ (Fig. 3). Owing to the plasticity of silver, some rays were 

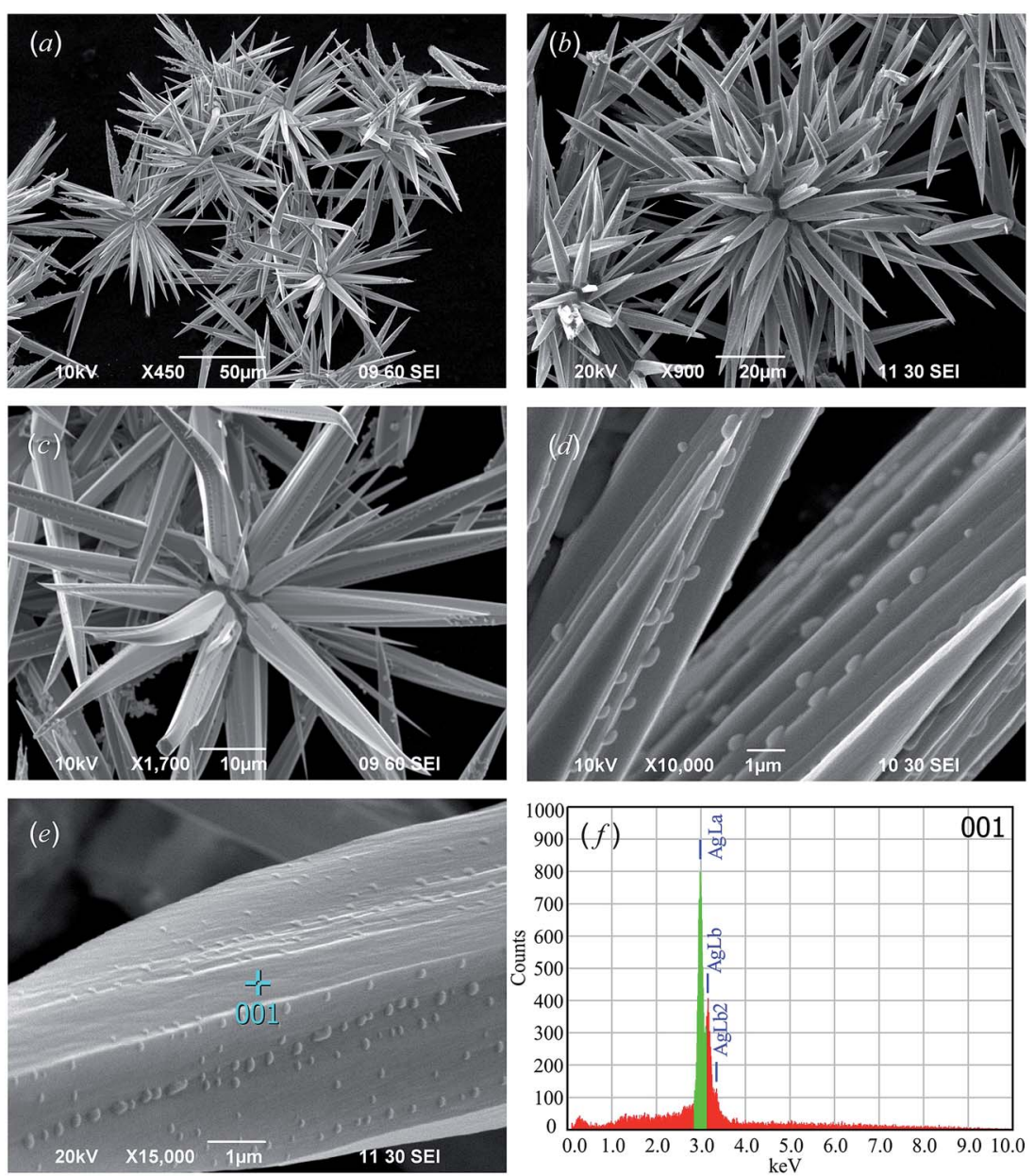

Fig. 3 The SEM images $(a-c)$ of stellate Ag particles and ( $d$ and e) their rays. (e and f) Area on which the EDX analysis of silver particles was performed, and the results of the EDX analysis, respectively. According to the EDX data, the particles contain $99.9 \pm 0.1$ wt\% silver, i.e. they are metallic Ag.

distorted during sample preparation. Fig. 3e displays a microphotograph of a stellate $\mathrm{Ag}$ particle ray with an indication of the scanning area on which the energy-dispersive X-ray (EDX) analysis was performed. The cumulative elemental EDX analysis is presented in Fig. 3f. According to the EDX data, the examined film contains $99.9 \pm 0.1 \mathrm{wt} \%$ silver, i.e. it is metallic Ag.

It can be supposed that the silver sulfide nanoparticles appearing at the initial stage of synthesis promote the deposition of $\mathrm{Ag}$ atoms, which form stellate silver particles during subsequent growth. This can be confirmed by the presence of a small amount of silver impurity on the XRD patterns of $\mathrm{Ag}_{2} \mathrm{~S}$ deposits. A similar effect of initially formed $\mathrm{Ag}_{2} \mathrm{~S}$ clusters on heterogeneous nucleation of silver nanoparticles in the form of cubes was described in previous work. ${ }^{15}$

Gradual growth of silver rays in different directions (Fig. 3) decreases the wettability of stellate particles since they repel liquid as a result of air capture by the space between the rays, i.e. the microscopic texture of the rough surface. Earlier it was shown that multi-scale topography of the relief strengthens the water repellency of surfaces (the so-called "lotus effect").9,45

Theoretical analysis and model calculations of volume, mass, relative density and specific surface area of stellate silver particles depending on the size of particles, numbers and lengths of rays are presented in the ESI file. $\dagger$

The total real volume $V_{\text {part }}$ of a stellate particle is equal to the sum of the volumes of its core and rays, i.e. $V_{\text {part }}=(4 \pi / 3) r^{2}(r+h)$ where $r$ is the radius of the particle core and $h$ is the length (height) of ray (see ESI $\dagger$ ). The volume $V_{\text {nonwet }}$ of space occupied by a stellate $\mathrm{Ag}$ particle in the case of nonwettability of its rays is tens of times larger than the real volume $V_{\text {part }}$ of silver entering into the particle. The relative density of stellate particles can be theoretically determined as $\rho_{\text {stell }}=\left(V_{\text {part }} / V_{\text {nonwet }}\right) \rho_{\mathrm{Ag}}$, where $\rho_{\text {Ag }}=10.5 \mathrm{~g} \mathrm{~cm}^{-3}$ is the density of silver. For example, the volume $V_{\text {part }}$ of a 32-ray particle with a core with $3 \mu \mathrm{m}$ radius and the maximal distance between the ends of oppositely directed rays $L_{\text {max }}=27 \mu \mathrm{m}$ is equal to $\sim 510 \mu \mathrm{m}^{3}$. The volume $V_{\text {nonwet }}$ of space occupied by this particle with the assumption of partial nonwettability of its rays is $\sim 5280 \mu \mathrm{m}^{3}$ (Table S1, ESI $\dagger$ ). Taking this into consideration, the relative density $\rho_{\text {stell }}$ of stellate $\mathrm{Ag}$ particles of such size is $\sim 1.01 \mathrm{~g} \mathrm{~cm}^{-3}$, i.e. slightly larger than the density of water. As the ray length increases, the relative density $\rho_{\text {stell }}$ of stellate Ag particles lowers. For example, the volume $V_{\text {part }}$ of a 32-ray particle with the same core size but with the maximal distance between the ends of oppositely directed rays 
$L_{\max }=70 \mu \mathrm{m}$ is equal to $\sim 1320 \mu \mathrm{m}^{3}$. The volume $V$ of space occupied by this particle is equal to $\sim 91950 \mu^{3}$, and the relative density $\rho_{\text {stell }}$ is only $\sim 0.15 \mathrm{~g} \mathrm{~cm}^{-3}$ (Table S1, ESI $\dagger$ ). Thus, as the ray length (height) increases, the relative density $\rho_{\text {stell }}$ of stellate Ag particles becomes smaller than the density of aqueous solution, and the particles come to the surface of the solution. Indeed, a film of stellate $\mathrm{Ag}$ particles does not appear on the surface of the solution at once, but a day after the beginning of the synthesis. The model dependence of the relative density $\rho_{\text {stell }}$ of stellate $\mathrm{Ag}$ particles on the core radius $r$ and length (height) $h$ of the rays is displayed in Fig. 4.

Experimental measurements of the density of fine-dispersed $\mathrm{Ag}$ powders prepared from the reaction mixtures (1) and (2) gave values $0.40 \pm 0.20$ and $0.37 \pm 0.20 \mathrm{~g} \mathrm{~cm}^{-3}$, respectively, which satisfactorily agree with the estimated values of relative density $\rho_{\text {stell }}$ (Table 1). A large measurement error is caused by the small mass of powder studied. The measured low density of $\mathrm{Ag}$ powder is its relative density $\rho_{\text {stell }}$, the magnitude of which is caused by the superhydrophobicity of the powder owing to the almost full nonwettability of the surface. Earlier, the influence of superhydrophobicity of powders on reduction of their measured density was explained in previous work. ${ }^{\mathbf{4 6}}$

The coexistence of $\mathrm{Ag}$ and $\mathrm{Ag}_{2} \mathrm{~S}$ particles both in the film on the glass walls and in the deposit at the bottom of the glass is confirmed by the SEM data (Fig. 5 and 6).

Fig. 5 shows an SEM image of the film taken from the glass wall. Silver sulfide is a semiconductor, and silver is a metal, therefore during electron microscopy studies silver emits more strongly than silver sulfide. On the SEM image this manifests itself in different color shades: silver looks more bright and light, while silver sulfide has a grey color. At first, metallic silver nuclei appear on the dark-grey film of $\mathrm{Ag}_{2} \mathrm{~S}$, which are seen as light spots. Then silver nuclei grow giving rise to cubic particles of size 2-3 $\mu \mathrm{m}$. Stellate silver particles with ingrown rays are seen to the left of the center. The growth of rays in different directions leads to the gradual formation of large stellate particles.

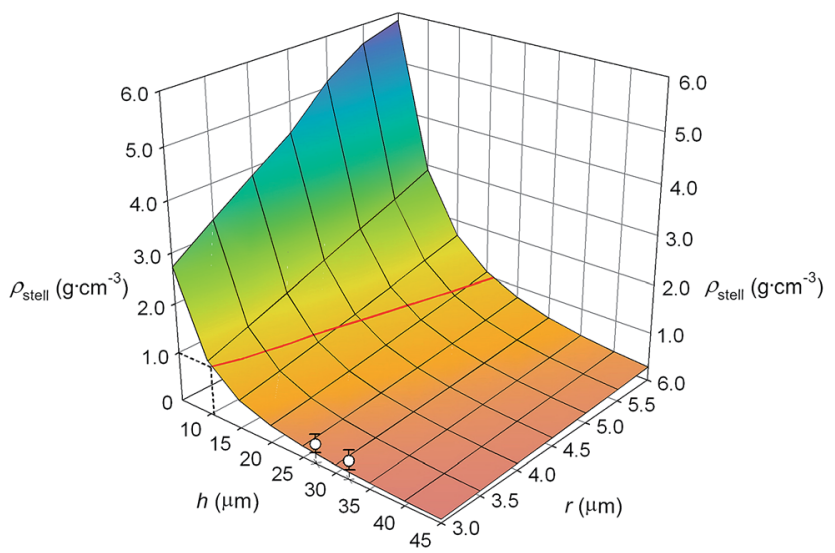

Fig. 4 Relative density $\rho_{\text {stell }}$ of stellate Ag particles as a function of core radius $r$ and ray length (height) $h$. The density of the aqueous solution is shown by the red line. (O) experimentally measured relative density $\rho_{\text {stell }}$ of fine-dispersed $\mathrm{Ag}$ powders prepared from the reaction mixtures (1) and (2).

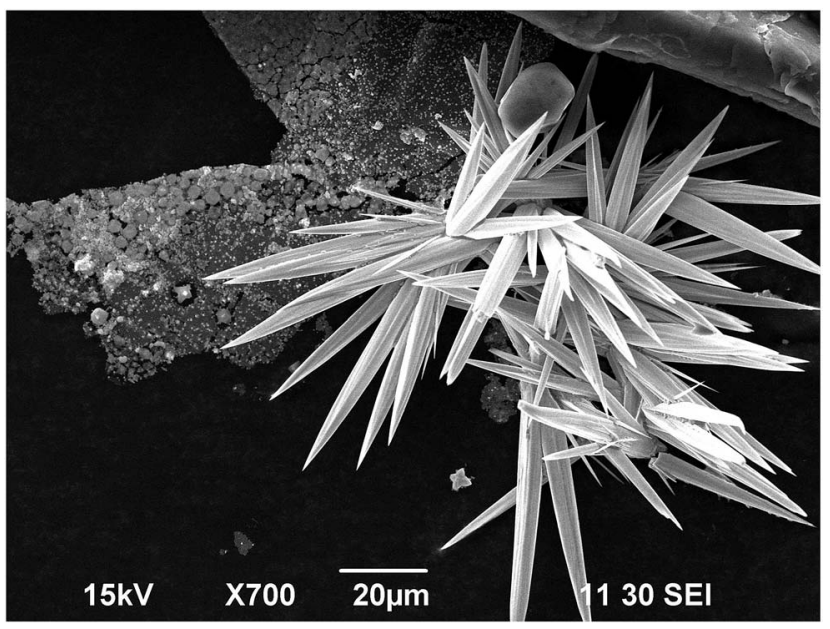

Fig. 5 SEM image of a film deposited on the glass walls. A dark-grey film of $\mathrm{Ag}_{2} \mathrm{~S}$ with light nuclei of silver particles and ingrown multi-ray Ag particles are visible.

Silver sulfide nanoparticles and ingrown silver rays in the deposit taken from the glass bottom after 1 day of exposure of the solution to light are demonstrated in Fig. 6. The agglomerates formed by $\mathrm{Ag}_{2} \mathrm{~S}$ nanoparticles less than $100 \mathrm{~nm}$ in size resemble small blossom clusters. A compact bundle of long silver rays is well visible in the center, and the same compactly connected silver rays are seen at the top on the right. The silver rays in the observed $\mathrm{Ag}$ particles grew only in opposite directions. The density of such Ag particles is greater than that of the aqueous solution, and they do not come to the surface of the solution, but remain in the deposit.

Four stages of silver particles growth from nucleation to stellate Ag particles are shown in Fig. 7. Primarily, Ag nuclei appear on the silver sulfide film. In the second stage, cubic Ag particles with edge length $0.5-0.8 \mu \mathrm{m}$ grow from the nuclei. In

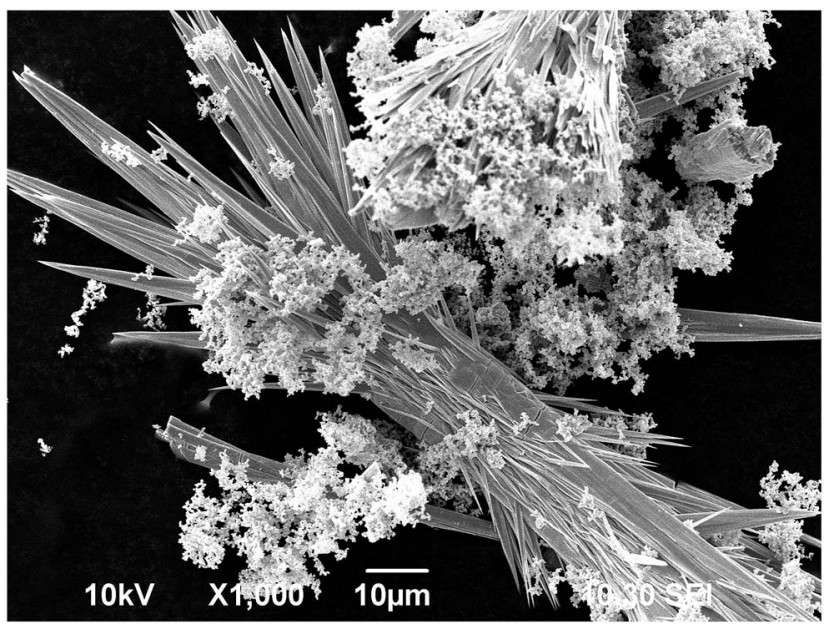

Fig. 6 SEM image of deposit from the bottom of the glass. The agglomerates resembling small blossom clusters are formed by $\mathrm{Ag}_{2} \mathrm{~S}$ nanoparticles. The long silver rays are united into compact particle bundles having a large relative density; therefore, such Ag particles do not come to the surface, but remain in the deposit. 


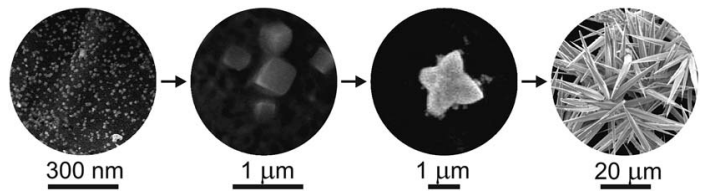

Fig. 7 The sequence of silver particle growth from nuclei to stellate Ag particles.

the third stage, rays begin to grow at the vertices of the cubic particles and the particle size becomes as much as $2-3 \mu \mathrm{m}$. The last stage represents gradual growth of long rays and the final formation of large stellate sea-urchin-like particles.

The particles of metallic silver show a characteristic reflectance and absorption in the visible range of $390-450 \mathrm{~nm}$ of the electromagnetic spectrum owing to surface plasmon resonance (SPR). The position of the band caused by the SPR depends on the size and the shape of the silver particles. For example, for spherical $\mathrm{Ag}$ nanoparticles $30-140 \mathrm{~nm}$ in size, the band was observed in the region of $400-460 \mathrm{~nm},{ }^{47}$ and for $\mathrm{Ag}$ nanofibers with a diameter of $12-20 \mathrm{~nm}$, the absorption peak was observed at $376 \mathrm{~nm} .{ }^{48}$ Several bands can be observed in the absorption spectra of larger particles of complex shape with sharp edges. For example, for planar triangular Ag nanoprisms with edge length of $\sim 200 \mathrm{~nm}$ and thickness of $\sim 20 \mathrm{~nm}$, absorption spectra display two peaks located at 342 and $932 \mathrm{~nm}^{.9}$

We measured the reflectance spectra of synthesized finedispersed powders from stellate $\mathrm{Ag}$ particles. In order to transform the reflectance spectra to the absorption spectra, the reflection function $F\left(R_{\infty}\right)=(1-R)^{2} /(2 R)$ is used. Function $F\left(R_{\infty}\right)$ $=(1-R)^{2} / 2 R$ is determined from the reflectivity $R$, measured in relative units, and is proportional to the absorption coefficient $\sigma(\omega)$, i.e. $F\left(R_{\infty}\right) \sim \sigma(\omega)$. UV-vis reflectance and absorption spectra of fine-dispersed powders from stellate Ag particles with $L_{\max }=$ 60 and $80 \mathrm{~nm}$, constructed in the coordinates " $F\left(R_{\infty}\right)-(\lambda)$ ", are shown in Fig. 8. These Ag powders were synthesized from reaction mixtures (1) and (3) (Table 1).

The UV-vis reflectance and absorption spectra of the powder of stellate $\mathrm{Ag}$ particles contain an intense peak in the region of $300-315 \mathrm{~nm}$ and a weak line in the region of about $370 \mathrm{~nm}$, which correspond to metallic silver. In the UV-vis reflectance and absorption spectra of the $\mathrm{Ag}$ powder synthesized from reaction mixture (3) and containing larger silver particles, the most intense peak is observed at about $304 \mathrm{~nm}$. For the $\mathrm{Ag}$ powder with smaller particles synthesized from reaction mixture (1), the intense peak is present in the UV-vis spectra at $\sim 317$ nm (Fig. 8).

Fig. 9 displays a UV-vis absorption spectrum of a film of stellate Ag particles on a glass substrate. Apparently, strong absorption without separation into individual peaks is caused by the sufficiently large film thickness, which is more than $30 \mu \mathrm{m}$. A wide absorption band is present in the interval from 280 to $550 \mathrm{~nm}$, an explicit maximum of absorption is observed at $\sim 320 \mathrm{~nm}$, and there is also a shoulder in the region of 450$460 \mathrm{~nm}$. The etching of Ag film led to a general decrease in absorption, but it was not possible to separate the individual peaks.
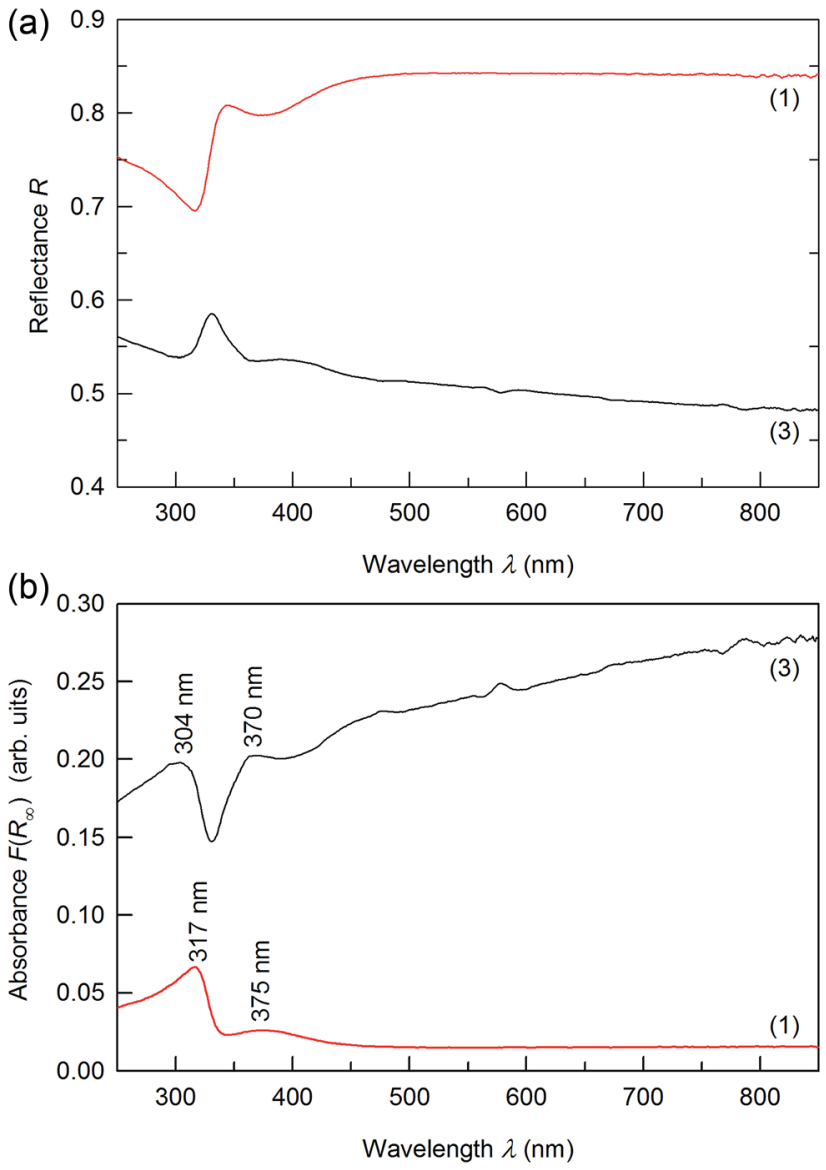

Fig. 8 The UV-vis spectra of (a) optical reflectance and (b) absorption of fine-dispersed powders synthesized from reaction mixtures (1) and (3) (Table 1).

The stellate Ag particles produced from the solution with $\mathrm{pH}=10$ have the largest ray length and the lowest relative density (Table 1).

Silver powder with stellate particle morphology can be synthesized only in reaction mixtures with the

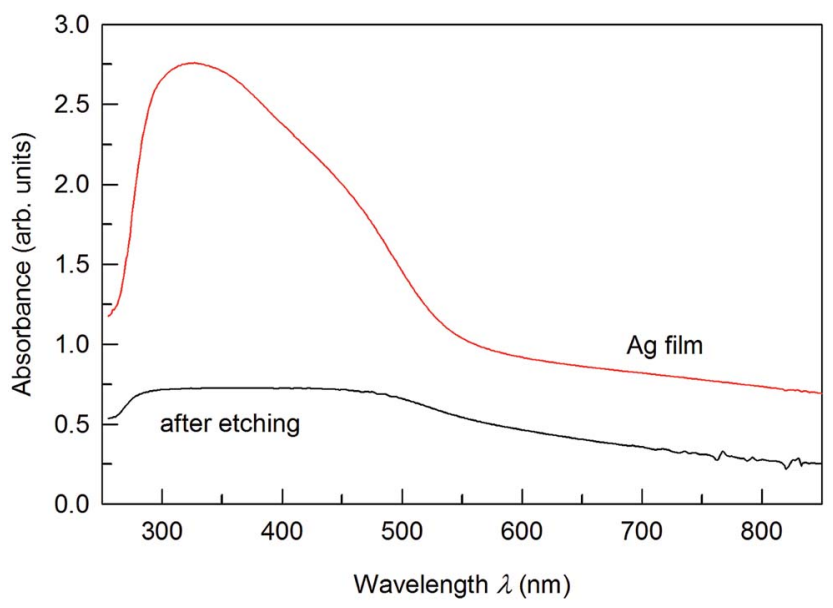

Fig. 9 The UV-vis spectrum of optical absorption of film from stellate Ag particles. 
$\left[\mathrm{AgNO}_{3}\right]:\left[\left(\mathrm{NH}_{2}\right)_{2} \mathrm{CS}\right]:\left[\mathrm{NH}_{4} \mathrm{OH}\right]$ concentration ratio ranging from $1: 0.1: 0.001$ to $1: 0.1: 0.1$. If the relative concentration of ammonium hydroxide in the reaction mixture is less than 0.001 , thiocarbamide does not dissociate with the formation of cyanamide $\mathrm{N}_{2} \mathrm{H}_{2} \mathrm{C}$, and silver is not reduced. If the relative concentration of ammonium hydroxide in the reaction mixture is larger than 0.1, the formation of silver sulfide becomes the main reaction. Silver sulfide is also formed when the relative concentration of thiocarbamide in the reaction mixture is larger than 0.1 .

On the one hand, the multi-ray silver particles have a distorted shape resembling stellate polyhedra ranging from a great 20-ray stellate dodecahedron to a large 60-vertex stellate icosahedron $\left(17^{\text {th }}\right.$ stellation of icosahedron) (Fig. 10). The ray length of stellate $\mathrm{Ag}$ particles is determined by the conditions of synthesis and is not connected with the symmetry relations typical of stellate polyhedra. On the other hand, the synthesized silver particles with long thin rays resemble sea urchins.

The growth of rays can be owing to uneven distribution of static charges on the nuclei surface. It is known that enhanced charge is observed on sharp ends of solid particles. Apparently, the growth of rays beginning at the vertices of cubic silver nuclei is due to the negative static charge of vertices, to which $\mathrm{Ag}^{+}$ cations are attracted. The growth of rays in the direction from the center to the vertices of the cubic nucleus corresponds to successive occupation of (111) planes and equivalent planes with the largest atomic density by silver atoms and is in agreement with the presence of preferable orientation in the direction [111] in the examined Ag particles as revealed with the XRD method.

The synthesized fine-dispersed powder containing stellate silver particles with the maximal distance between the ends of oppositely directed rays $L_{\max }=60-70 \mu \mathrm{m}$ has a small relative density of $0.21-0.15 \mathrm{~g} \mathrm{~cm}^{-3}$ (Table S1, ESI $\dagger$ ), which is less than the density of water. Due to this fact, as well as to low wettability, the synthesized powder comes to the surface of the reaction solution in the form of a film, which considerably facilitates its removal from the mother solution. An important advantage of the fine-dispersed silver powder is the low wettability of its particles, which serves as a prerequisite for potential application of this powder or films made thereof as superhydrophobic materials. The superhydrophobicity of a surface is connected with its topology, texture and roughness, or the roughness of its individual particles..$^{50}$ Preliminary measurement of the limiting wetting angle (or contact angle) $\theta$ of the synthesized silver film wetted with distilled water (Fig. 11)

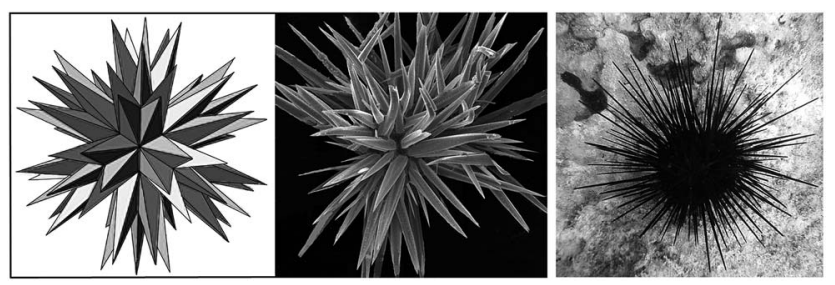

Fig. 10 The appearance of a 60-vertex stellate icosahedron, synthesized stellate Ag particle and sea-urchin (from left to right).

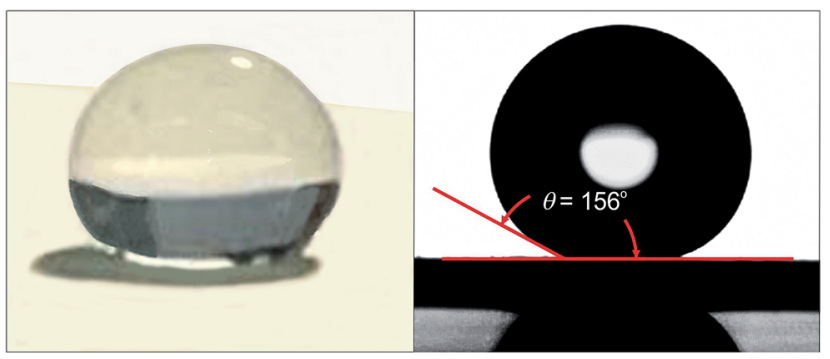

Fig. 11 A water droplet on the surface of the film of stellate $\mathrm{Ag}$ particles. The contact angle $\theta$ is equal to $\sim 156^{\circ}$.

showed that the contact angle $\theta$ is equal to $155-160^{\circ}$, whereas that of ordinary silver is from 38 to $63^{\circ}$.

The combination of specific morphology and roughness with low surface energy is responsible for the superhydrophobicity and provides the stability of superhydrophobic surfaces. Indeed, in the simple case, the wetting of a surface by a liquid is determined by the energy of interaction of the liquid with this surface and is characterized by a wetting angle $\theta$. Equilibrium wetting angle depends on the surface tension at the interfaces of liquid and solid phases. The Wenzel-Cassie model $^{51,52}$ is used for the description of superhydrophobic surfaces of nanopowders, when the cavities of a surface texture are filled by air.

The contact angle of the Ag film is $\sim 156^{\circ}$ (Fig. 11). This result indicates that the superhydrophobic film from stellate $\mathrm{Ag}$ particles has a high surface roughness due to the Ag particle morphology and low surface free energy. The little shape deformation of the water droplet observed under the influence of its weight also proves that the low surface energy of the $\mathrm{Ag}$ film studied is an important factor for its superhydrophobic properties.

It should be noted that superhydrophobic stellate Ag particles are still a rather exotic material. Sponge-based materials and mesh-based materials with soot, silica nanoparticles and others are the most widespread superhydrophobic materials (see, for example, a series of publications ${ }^{53-55}$ by Jian Li and coauthors).

In the synthesized fine-dispersed silver powder, owing to the particle morphology, the cavities of the surface texture are occupied by air, which provides their nonwettability with any liquids.

The specific surface area of stellate silver particles depends on the number and length of rays (see Table S2 and Fig. S1, ESI $\dagger$ ). In Fig. S1, $\dagger$ the region between the surfaces I and II corresponds to the specific surface area $S_{\mathrm{sp}}$, which is an average between the minimal (for stellate particles with conical rays) and the maximal (for stellate particles with rays in the form of a trihedral pyramid) specific surface area. For stellate Ag particles with core radius of $3 \mu \mathrm{m}$, the specific surface area ranges from 0.25 to $0.44 \mathrm{~m}^{2} \mathrm{~g}^{-1}$ (Table 1 ). This is 3-5 times more than the specific surface area of usual silver powders with average particle radius of $\sim 3 \mu \mathrm{m}$.

Unlike other methods of synthesis of sea-urchin-like particles described in the literature, ${ }^{34-38}$ the specificity of preparing stellate silver particles by the method of chemical reduction is 
directly related to the participation of $\mathrm{Ag}$ in photochemical reactions, which are the basis of the proposed method. We do not exclude the possibility of synthesis of stellate particles of other metals by the described method, but this is an independent problem.

\section{Conclusion}

The prepared fine-dispersed silver powder is a promising material for application in various fields of engineering, electronics and medicine. Thanks to the unique morphology of Ag particles, the synthesized powder possesses a reduced relative density and a large specific surface area with a considerable number of atoms located on the faces, edges and vertices of particles. Owing to the high chemical resistance of silver to alkalis and the low wettability of the produced fine-dispersed powder, it holds promise as a material for coating conduit walls in the chemical industry.

The location of a large number of atoms on the faces and especially edges and vertices of the stellate particles make the synthesized Ag powder an attractive material for application in catalysis. On the one hand, it can be used directly as a catalyst for hydrogen evolution from aqueous solutions under visible light irradiation. On the other hand, owing to the large specific surface area, the fine-dispersed $\mathrm{Ag}$ powder can serve as a catalyst support.

\section{Conflicts of interest}

There are no conflicts to declare.

\section{Acknowledgements}

This study was supported by the Russian Science Foundation (grant no. 14-23-00025) through the Institute of Solid State Chemistry of the Ural Branch of the RAS. Authors are grateful to Dr I. I. Leonidov and Mr I. D. Popov for the help in measuring optical properties, and $\mathrm{Mr}$ F. Heib for contact angle measurement.

\section{References}

1 Z. Shan, J. Wu, F. Xu, F.-Q. Huang and H. Ding, J. Phys. Chem. C, 2008, 112, 15423-15428.

2 P. Christopher, H. Xin and S. Linic, Nat. Chem., 2011, 3, 467472.

3 G. Pistoia, Battery Operated Devices and Systems: From Portable Electronics to Industrial Products, Elsevier, Amsterdam, 2009, p. 408.

4 H. D. Yun, D. M. Seo, M. Y. Lee, S. Y. Kwon and L. S. Park, Metals, 2016, 6, 14.

5 P. Jain and T. Pradeep, Biotechnol. Bioeng., 2005, 90, 59-63.

6 J. Fabrega, S. N. Luoma, C. R. Tyler, T. S. Galloway and J. R. Lead, Environ. Int., 2011, 37, 517-531.

7 M. Rai, A. Yadav and A. Gade, Biotechnol. Adv., 2009, 27, 7683.

8 J. Pulit-Prociak and M. Banach, Open Chem., 2016, 14, 76-91.
9 C. H. Choi, U. Ulmanella, J. Kim, C. M. Ho and C. J. Kim, Phys. Fluids, 2006, 18, 087105.

10 N. Zhao, F. Shi, Z. Q. Wang and X. Zhang, Langmuir, 2005, 21, 4713-4716.

11 L. Yang, S. Bai, D. Zhu, Z. Yang, M. Zhang, Z. Zhang, E. Chen and W. Cao, J. Phys. Chem. C, 2007, 111, 431-434.

12 A. Panneerselvam, M. A. Malik, P. O'Brien and J. Raftery, J. Mater. Chem., 2008, 18, 3264-3269.

13 K. Akamatsu, S. Takei, M. Mizuhata, A. Kajinami, S. Deki, S. Takeoka, M. Fujii, S. Hayashi and K. Yamamoto, Thin Solid Films, 2000, 359, 55-60.

14 L. Gao, P. Härter, C. Linsmeier, A. Wiltner, R. Emling and D. Schmitt-Landsiedel, Microelectron. Eng., 2005, 82, 296300.

15 A. Ruditskiy and Y. Xia, J. Am. Chem. Soc., 2016, 138, 31613167.

16 X. Xie, M. Wei, L. Du, Y. Nie, X. Qi, Y. Shao and Z. Wei, J. Mater. Chem. A, 2017, 5, 15390-15394.

17 H. Sakai, T. Kanda, H. Shibata, T. Ohkubo and M. Abe, J. Am. Chem. Soc., 2006, 128, 4944-4945.

18 H. Liang, Q. Tang, K. Yu, S. Li and J. Ke, Mater. Lett., 2007, 61, 1020-1022.

19 X. Fan, X. Qin, L. Jing, Y. Luan and M. Xie, Mater. Res. Bull., 2012, 47, 3732-3737.

20 K. Shameli, M. B. Ahmad, A. Zamanian, P. Sangpour, P. Shabanzadeh, Y. Abdollahi and M. Zargar, Int. J. Nanomed., 2012, 7, 5603-5610.

21 S. I. Sadovnikov and A. I. Gusev, Eur. J. Inorg. Chem., 2016, 2016, 4944-4957.

22 S. I. Sadovnikov and A. I. Gusev, J. Mater. Chem. A, 2017, 5, 17676-17704.

23 V. M. Maksimović, M. G. Pavlović, L. J. Pavlović, M. V. Tomić and V. D. Jović, Hydrometallurgy, 2007, 86, 22-26.

24 L. Avramović, M. M. Pavlović, V. M. Maksimović, M. Vuković, J. S. Stevanović, M. Bugarin and N. D. Nikolić, Metals, 2017, 7, 160 .

25 S. Kaniyankandy, J. Nuwad, C. Thinaharan, G. K. Dey and C. G. S. Pillai, Nanotechnology, 2007, 18, 125610.

26 P. S. Mdluli and N. Revaprasadu, Mater. Lett., 2009, 63, 447450.

27 J. H. Jung, H. C. Oh, H. S. Noh, J. H. Ji and S. S. Kim, Aerosol Sci., 2006, 37, 1662-1670.

28 Y. H. Chen and C. S. Yeh, Colloids Surf., A, 2002, 197, 133139.

29 M. Kawasaki and N. Nishimura, Appl. Surf. Sci., 2006, 253, 2208-2216.

30 K. M. M. Abou El-Nour, A. Eftaiha, A. Al-Warthan and R. A. A. Ammar, Arabian J. Chem., 2010, 3, 135-140.

31 D. M. Ledwith, A. M. Whelan and J. M. Kelly, J. Mater. Chem., 2007, 17, 2459-2464.

32 D. O. Yener, J. Sindel, C. A. Randall and J. H. Adair, Langmuir, 2002, 18, 8692-8699.

33 G. Wei, H. Zhou, Z. Liu, Y. Song, L. Wang, L. Sun and Z. Li, J. Phys. Chem. B, 2005, 109, 8738-8743.

34 E. Jerby, A. Golts, Y. Shamir, S. Wonde, J. B. A. Mitchell, J. L. LeGarrec, T. Narayanan, M. Sztucki, D. Ashkenazi, Z. Barkay and N. Eliaz, Appl. Phys. Lett., 2009, 95, 195501. 
35 F. Ma, J. Huang, J. Li and Q. Li, J. Nanosci. Nanotechnol., 2008, 9, 1-5.

36 H. Hu and K. Sugawara, J. Chem. Eng. Jpn., 2009, 42, s85-s89. 37 J. Ma, A. Hui, J. Liu and Y. Bao, Mater. Lett., 2015, 158, 420423.

38 H. Chen, S. Y. Ma, H. Y. Jiao, G. J. Yang, X. L. Xu, T. T. Wang, X. H. Jiang and Z. Y. Zhang, J. Alloys Compd., 2016, 687, 342-351. 39 X'Pert HighScore Plus. Version 2.2e (2.2.5)@, PANalytical B. V., Almedo, the Netherlands, 2009.

40 Match! Version 1.10. Phase Identification from Powder Diffraction@, Crystal Impact, 2003-2010.

41 S. I. Sadovnikov, A. I. Gusev and A. A. Rempel, Superlattices Microstruct., 2015, 83, 35-47.

42 S. I. Sadovnikov, A. I. Gusev and A. A. Rempel, Phys. Chem. Chem. Phys., 2015, 17, 12466-12471.

43 S. I. Sadovnikov, A. I. Gusev, A. V. Chukin and A. A. Rempel, Phys. Chem. Chem. Phys., 2016, 18, 4617-4626.

44 P. Patnaik, Dean's Analytical Chemistry Handbook, McGrawHill, New York, 2nd edn, 2004, Table 4.2, p. 1280.
45 E. Bormashenko, R. Grynyov, G. Chaniel, H. Taitelbaum and Y. Bormashenko, Appl. Surf. Sci., 2013, 270, 98-103.

46 A. S. Kurlov and A. I. Gusev, Phys. Solid State, 2016, 58, 16871693.

47 D. D. Evanoff and G. Chumanov, ChemPhysChem, 2005, 6, 1221-1231.

48 H. Wang and L. Qi, Adv. Funct. Mater., 2008, 18, 1249-1256. 49 S. Xiong, B. Xi, K. Zhang, Y. Chen, J. Jiang, J. Hu and H. C. Zeng, Sci. Rep., 2013, 3, 2177.

50 D. Quere, Annu. Rev. Mater. Res., 2008, 38, 71-99.

51 R. N. Wenzel, Ind. Eng. Chem., 1936, 28, 988-994.

52 A. B. D. Cassie and S. Baxter, Nature, 1945, 155, 21-22.

53 J. Li, R. Kang, X. Tang, H. She, Y. Yang and F. Zha, Nanoscale, 2016, 8, 7638-7645.

54 J. Li, L. Yan, X. Tang, H. Feng, D. Hu and F. Zha, Adv. Mater. Interfaces, 2016, 3, 1500770.

55 J. Li, C. Xu, Y. Zhang, R. Wang, F. Zha and H. She, J. Mater. Chem. A, 2016, 4, 15546-15553. 